\title{
Fragmenteista kuvaan ja maisematilaan
}

\author{
Marja-Terttu Kivirinta
}

Anna Ripatti, Jukka Cadogan ja Linda

Leskinen (toim.) Fragmentti, muisto, maisema.

Ville Lukkarisen kirjoituksia taiteesta ja

arkkitehtuurista. Taidehistoriallisia tutkimuksia.

Konsthistoriska studier 48. Helsinki:

Taidehistorian Seura, 2017.

Taidehistorian Seuran julkaisema Taidehistoriallisia tutkimuksia 48, Helsingin yliopiston taidehistorian professori Ville Lukkarisen 60-vuotispäiväksi keväällä 2017 ilmestynyt perusteellinen juhlakirja, alkaa esipuheen jälkeen perinteisellä "tabula graturatorialla". Kolmeen temaattiseen osaan jäsentyvä kirja koostuu Lukkarisen vuosina 1998-2017 julkaistuista artikkeleista, jotka keskittyvät kuva-, kuvitus- ja rakennustaiteen historiaan. Yksi niistä uppoutuu pienoismalleihin todellisuuden pienoismaailmoina. Kokonaisuuteen limittyvät myös okkultismi, kosmisiin näkemyksiin viittaava symbolistinen arkkitehtuuri, tai Lukkarisen oma-

kin harrastus, maisematilaan eläytyvä piirtäminen, joka tulee esille ainakin sivulauseissa. Sekin kuuluu tutkimusmetodeihin.

Toisaalla aiheena on taas lapsuuden ja nuoruuden asuinlähiö, modernin edistyksellisenä pidetty Helsingin Pihlajamäki, joka Lukkarisen muistoissa saa hiukan toisenlaisen näkökulman kuin usein vain alueen silloin uuteen kerrostaloarkkitehtuuriin keskittyvä 1960-lukulainen uljas urbaani maailmankuva. Ympäristön eläytyvä kokeminen on Ville Lukkariselle selkeä metodinen valinta taidehistorioitsijan työssä. Kirjan kaikki artikkelit ilmentävät sitä tavalla tai toisella. Lukija ymmärtää sen jo hänen kuvataiteen historiaan keskittyvistä kirjoituksistaan, jotka kirjan ensimmäisessä osassa edustavat hänen tuoreimpia julkaisujaan. Rakennustaiteen historiaan sijoittuvat artikkeleista varhaisimmat. Se on ymmärrettävää, sillä Lukkarinen itse oli aikoinaan professori Lars Petterssonin oppilas.

Kirjan sisältöön ja Lukkarisen työhön lukijaa valmistelee jo rakennustaiteen jatkumoa ilmentävä johdanto. Sen on kirjoittanut Lukkarisen taannoinen oppilas ja sittemmin hänen seuraajansa, Tampereen teknillisen yliopiston arkkitehtuurin historian professori Olli-Paavo Koponen, jonka artikkeli "Mitä arkkitehtuurista voi kertoa kuvataiteen avulla - Ville Lukkarisen kirjoitukset" on siksi paikallaan. Taidehistorian yliopisto-opetuksen historiografiassa Lukkarinen kuuluu professoreihin, jonka erityisalaa on arkkitehtuurin lisäksi myös kuva- ja kuvitustaide. Myös nykytaiteella on roolinsa. Lukkarinen on kirjoittanut ja kirjoittaa yhä moniin nykytaiteilijoiden näyttelykirjoihin, mitä Koponenkin havainnollistaa esimerkeillään muun muassa taiteen keinoin tehdyistä aineettoman tai aineellisen arkkitehtuurin kuvauksista. Lukkarisen artikkeleista juhlakirjaan valitut 2000-luvun alun George Segal ja Kain Tapper -tekstit liittyvät jo nykytaiteen historiaan.

Johdatellessaan lukijaa artikkelikokoelmaan OIli-Paavo Koponen huomioi keskeisen seikan Lukkarisessa kirjoittajana. Tälle on ominaista ilmentää näkemäänsä rakentaessaan artikkelien kerrontaa, josta Koposen mukaan muodostuu eräänlainen "narratiivinen matka". Se ulottuu taiteilijasta ja hänen teoksis- 


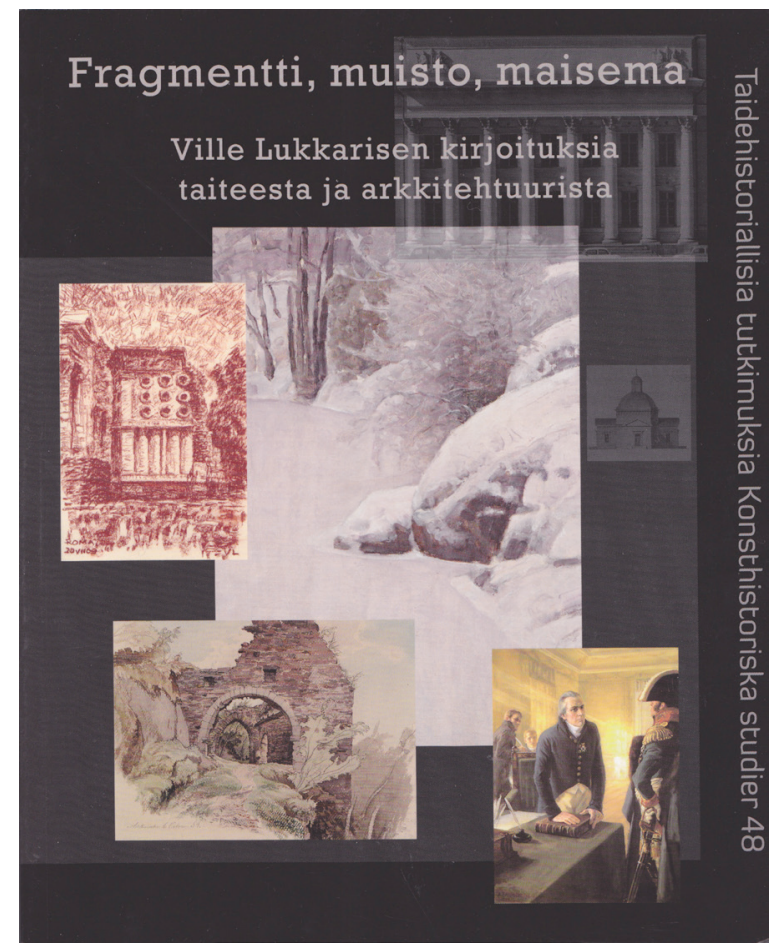

taan erilaisten taide- ja teoriakontekstien viitoittaman tien kautta takaisin jo tekstien alussa esitellyn aiheen tarkempaan syvätarkasteluun, tulkintaan.

Lukkarisen uutteruus tutkijana ja kirjoittajana ilmenee hänen itsensä artikkelikokoelman yhteyteen toimittamastaan julkaisuluettelosta. Julkaisuja, artikkeleita ja yleistajuisia tutkimuksia on runsaasti vuodesta 1982 lähtien. Hän on aiemmin kirjoittanut ja esitelmöinyt muun muassa Pekka Halosesta, jonka taidetta käsittelee myös hänen kirjansa Pekka Halonen- pyhä taide (SKS 2007). Juhlakirjaan valittu vuoden 2005 artikkeli ilmestyi sitä ennen. Se keskittyy Haloseen ja tämän taiteeseen lähinnä ympäristöpolitiikan näkökulmasta.

\section{Käsitteet ja varhaisromantiikka}

Kirjan tulkinta on hyvä aloittaa otsikosta, Fragmentti, muisto, maisema. Ville Lukkarisen kirjoituksia taiteesta ja arkkitehtuurista. Se nostaa heti esille käsitteitä, jotka kantavat julkaisun tekstejä, oli kyse sitten Akseli Gallen-Kallelasta, Pekka Halosesta, Werner Holmbergista, Albert Edelfeltistä, Lauri Anttilasta, Carl Ludvig Engelin Kansalliskirjastosta tai Kuorikoskien kirkoista. "Fragmentti", "muisto" ja "maisema" ovat keskeisiä taiteessa ja arkkitehtuurissa, joita Lukkarinen tarkastelee.

Fragmentti, muisto ja maisema sitovat Lukkarisen omankin asiantuntijuuden 1800-luvun varhaisromantiikkaan. Se avautuu perusteellisesti erityisesti Lauri Anttilan (s. 1938) juhlakirjassa vuonna 2008 julkaistusta "Werner Holmberg ja fragmentin taide" -artikkelista. Anttilan käsitetaiteen kautta Lukkarinen esittää kysymyksen, jolla on taidehistoriallista merkitystä. Hän päätyy erittelemään sitä, mitä Werner Holmbergin (1830-60) taiteesta voi saada irti, kun sitä tarkastelee varhaisromantiikasta kiinnostuneen Lauri Anttilan monista fragmenteista koostuvien käsitteellisten vaellusteosten kautta.
Itse artikkeli on antoisaa luettavaa sillekin, joka oli luullut tuntevansa Anttilan taiteen jo hyvin; Holmbergin maalauksista ja piirustuksista puhumattakaan. Se osoittaa että täytyy ensin tietää mitä tarkoitetaan, kun puhutaan fragmenteista varhaisromantiikan merkkeinä taiteessa,

kirjallisuudessa ja filosofiassa. Sitten on esiteltävä perusteellisesti se, miten se liittyy Werner Holmbergin elämään ja taiteeseen. Sitä kautta päädytään vähitellen takaisin Lauri Anttilan vaellusteoksiin ja siihen, miten ne ovat käsitteellistäneet taiteilijan ympäristökokemuksia romantikkojen jalanjäljissä Saksassa tai Suomessa. Lopussa Hämeen hiekkatiellä ja Kurun rannan vaeltajana on itse artikkelin kirjoittaja, taidehistorioitsija Lukkarinen. Vuonna 2007 hän on nähnyt hyvin toisenlaisen maiseman kuin samaa ympäristöä 1980-luvun puolivälissä dokumentoinut Anttila. Maailma on muuttunut jo parissa vuosikymmenessä. Puhumattakaan siitä, millaisena maisemana Kurun Leppälahti oli avautunut Werner Holmbergille 1850-60 -lukujen vaihteessa.

Tätä kautta myös minä lukijana aloin vähitellen vakuuttua siitä, että jo varhaisen kuoleman takia lyhyeksi jäänyt Werner Holmbergin elämäntyö ei kenties ole aiemmassa tutkimuksessa esitettyä "realismia", ulkoista todellisuutta sellaisenaan jäljentävää luonnon- ja kulttuurinäkymien taltiointia. Sen sijaan Holmbergin maisemataide koostuu paikan päällä tehdyistä tutkiel- 
mista, fragmenteista, sekä eri aiheista ja yksityiskohdista myöhemmin sommitelluista kokonaisuuksista tai yksityiskohtien toistoista, jopa sarjallisuudesta.

Lukkarinen kirjoittaa capriccioista, "oikuista", eli invenzioineista. Ne ovat omia kokonaisuuksiaan, kuten myös sävellystaiteessa, jossa eri aihelmien taustalla ovat fragmenttien alkuperäiset kontekstit. Koko artikkeli sinällään on erinomainen esitys "fragmentista" käsitteenä. Se liittyy sittemmin 1900-Iuvun modernismissa yleistyneeseen ja myös eri materiaaleja koostavaan kollaasiin, ja varhaisromantiikan perua lienee myös ymmärrys taiteen prosessuaalisuudesta. Nykytaiteessa prosessi on oma ilmiönsä tänäänkin, mutta nyt keskiössä on myös katsoja, kuulija tai lukija

\section{Tuohilippi, alkuperäisyyden aate ja antimodernis- tin kaipuu erämaihin}

Juhlakirjan kannalta erityistä lienee se, että Ville Lukkarinen ei saanut julkaisua ikään kuin yllätyslahjaksi, vaan kirjahankkeesta informoituna häneltä tilattiin myös uusi artikkeli. Lukkarisen osuus käynnistyy heti tuoreella kirjoituksella "Akseli Gallen-Kallela tuohilipillä alkuperäisyyttä ammentamassa" (2017), joka on jatkoa hänen aiemmin aiheesta pitämälleen esitelmälle.

Kyseinen artikkeli runsaine yksityiskohtineen vie vuosikymmenien väleissä tehdyille taiteilijan matkoille: Vienan Karjalan laulumaiden kautta Britannian
Itä-Afrikkaan, Keniaan, ja sitten Uuteen Meksikoon. Keskiössä on taide ja 1920-luvun myöhäinen avainteos, jonka kautta Lukkarinen hahmottelee "alkuperäisyyden aatehistoriaa" Gallen-Kallelan taiteessa. Mutta kohteeksi on joutunut myös taiteilija, siis ennen kaikkea tämän alkuperäisyyttä tavoitelleen, Länsi-Suomesta lähtöisin olevan suomalaismielisen taidemaalarin ja piirtäjän asenne suhteessa luontoon ja hänen kuvittelemiinsa "luonnollisiin" inmisiin. Pettymykseksi hänen kiinnostuksensa kohteet olivat kuitenkin jo kulttuurin pilaamia.

Fragmentti, muisto ja maisema esiintyvät myös tässä juhlakirjan ensimmäisessä ja siis ainoassa aiemmin julkaisemattomassa artikkelissa. Sen lähtökohtana on Gallen-Kallelan luonnosmainen maalaus Metsästäjä uhrilähteellä (1925) - maalaus, joka on esitelty myös kirjan nelivärisessä kuvaliitteessä. Liitteessä julkaistusta kuvasta saa tuskin selvää teoksen vasemmassa alareunassa löytyvästä yksityiskohdasta, joka kuitenkin on artikkelin kannalta tärkeä. Maalaukseen tehty merkintä "TAOS 1925" kertoo, että taiteilija toteutti ja signeerasi maalauksen Yhdysvaltain Uudessa Meksikossa kyseisenä vuonna. Kalevala-aiheet kiinnostivat Gallen-Kallelaa tunnetusti miltei 40 vuotta.

Kohteena olevassa maalauksessa on myös toinen Lukkarisen uteliaisuuden herättänyt yksityiskohta, jo Gallen-Kallelan (so. Gallénin) varhaisessa kuvastos- sa esiintyvä etnografinen esine, tuohilippi. Lippi-aihe näyttäytyi ensi kertaa fennomaani Eliel Aspelinin ex libriksessä vuodelta 1897.

Gallen-Kallelan taiteen avaamisessa Lukkarisen apuneuvoina ovat jälleen varhaisromantiikan käsitteet, itseään luontoa eli alkuperäisyyttä edustava naiivi ja toisaalta sentimentaalinen. Jälkimmäinen on se, kulttuurin piiristä lähtöisin oleva ja Akseli Gallen-Kallelan edustama taiteilija, joka yrittää saada otteen kuvittelemastaan luonnosta. Dokumenttien mukaan Gallen-Kallela tunnisti asenteensa ja vähittäisen pettymyksensä. Siihen liittyy myös taidehistoriallisesti mielenkiintoinen seikka, jota teoksesta toiseen esiintyvä muinainen tuohilippikin edustaa.

Gallen-Kallela ei ollut taiteessaan niin kristillinen kuin joissakin tutkimuksissa on esitetty. Uuteen Meksikoon kotimaataan paennut taiteilija poti vielä 1920-luvulla kaipuutaan muinaissuomalaiseen alkuperäisyyteen, so. pakanalliseen kulttuuriin, tavalla joka sai jopa poliittisen ulottuvuuden. Pakanuus oli saanut väistyä hänen harmikseen kristinuskon tieltä, mitä hän oli käsitellyt jo yhdessä Pariisin vuoden 1900 maailmannäyttelyn Suomen paviljonkiin maalaamassaan kattofreskossa. Samaa aihetta kuvasi myös vuoden 1906 maalaus "Väinämöisen lähtö", jossa lipin sijasta esiintyi kantele. Näin Lukkarinen mainitsee Gallen-Kallelan pettyneen myös kristilliseen kirkkoon. 
Akseli Gallen-Kallela ei ollut ainoa alkuperäisyyden lähteille pyrkinyt taiteilija Suomessa tai Euroopassa. Teollisuutta ja urbanisoitumista paenneisiin 1800-luvun antimodernisteihin kuului Bretagnesta Tahitille luonnon ja naiivien inmisten piiriin etsiytynyt Paul Gauguin. Myös Gallen-Kallela ja Pekka Halonen jakoivat antimodernistisen kaipuun erämaihin ja tyytymättömyyden, jonka 1800-luvulla vauhtiin päässyt metsäteollisuus herätti. Taiteilijaystävyksillä oli yhteinen huolenaihe, vaikka he olivatkin lähtöisin erilaisista taustoista. Halonen kuului köyhtyneeseen savolaiseen talonpoikaissukuun, Gallen-Kallela oli säätyläisiä. Molemmat edustavat Suomen taidehistorian kaanonissa "mestareiksi" arvioituja (mies)taiteilijoita, kuten niin monet muutkin Lukkarisen tutkimat taiteilijat.

Myös Gallen-Kallelan tavoin metsäteollisuutta vastustava Halonen kaipasi "erämaita", vaikka hän ei niinkään unelmoinut inmisen koskemattomasta luonnosta. Hän oli antimodernisti, joka talonpojan poikana ymmärsi toisaalta kuitenkin kulttuuria, inmisen viljelemän maan merkityksen. Lukkarisen juhlakirjan ulkopuolelta tuleekin mieleeni, että joissakin nykyajassakin yhä vaikuttavissa ekologisissa ja ympäristöpoliittisissa suuntauksissa on vivahteita samasta aatehistoriallisesta perimästä, alkuperäisen luonnon osin turhautunuttakin etsintää.

\section{Tiedonvälitystä tutkimuksesta}

Arvioni alussa toin esille Ville Lukkarisen taidehistorioitsijan työn painottuneisuuden rakennustaiteeseen ja kuvataiteeseen sekä niiden yhteyksiin, joista juhlakirjan johdanto havainnollisesti muistuttaa. Itse kirjan otsikko on saanut minut viivähtämään kuitenkin "fragmentissa", "muistossa" ja "maisemassa", siten kuin ne ilmenevät havainnollisina Lukkarisen tuoreimmissa artikkeleissa, jotka keskittyvät niin kotimaisen taiteen 1800-1900 -lukuihin kuin myös täkäläisen nykytaiteen historiaan. Minulle kirjan artikkeleista erityisesti ne ovat avanneet luovaa tapaa, jolla Lukkarinen asettaa tulkitsemansa taiteen 1700-1800 -lukujen vaihteen aatemaailman perua olevan varhaisromantiikan perinteeseen. Sama omakohtaisuus ilmeni jo hänen tuoreimpiin teoksiinsa kuuluvassa, vuonna 2015 ilmestyneessä kirjassaan Piirtäjän maisema. Paikan kokeminen piirtämällä (SKS).

Ympäristön kokeminen, koskee se sitten arkkitehtuuria tai rakentamatonta maisemaa, on moniaistista Sen havainnointi asettuu aina johonkin tiedettyyn tai jopa tiedostamattomaan kehykseen, muistoon, kokemukseen tai konventioon, kuvaan, kirjaan tai teoriaan. Nyt arvioimastani julkaisusta ilmenee sekin, että ympäristö on tarkastelijansa, taiteilijan tai tutkijan kannalta tuskin lainkaan puhdasta, koskematonta luontoa. Sillä on kulttuurinen yhteytensä. Siitä syystä arvioinkin, että paitsi taidehistorian professorin juh- lakirjana Taidehistoriallisia tutkimuksia 48 -julkaisu toimii tiedonvälittäjänä alan tutkimuksen nykysuuntauksista. Ville Lukkarisen kohdalla kyse on hänen kiinnostuksella viljelemästään sarasta. Tällä tarkoitan tapaa pysytellä miestaiteen konventioissa ja perinteisen perustutkimuksen kehyksessä, mutta maltillisen avoimena ylittää taiteiden rajoja.

FT, taidehistorioitsija ja -kriitikko Marja-Terttu Kivirinta on nykyisin vapaa kirjoittaja, joka työskenteli aiemmin pitkään Helsingin Sanomien kulttuuritoimittajana. Kivirinnan kriittisen kiinnostuksen kohteita ovat taidehistorian historiografia, taiteilijoiden elämä ja taide -elämäkerrat ynnä muut kansalliset tai ylirajaiset kertomukset sukupuoleen, luokkaan ja muihin määritteisiin kiinnittyneinä esityksinä. Kivirinta seuraa vanhaa taidetta ja nykytaidetta myös kulttuurisesta näkökulmasta. 